\title{
Design and Calculation of Web-steel Building Structure based on AutoCAD Secondary Development
}

\author{
Yuchen LIU \\ Weifang University of Science \& Technology, Shouguang 262700 China \\ Dongseo University, Korea
}

\begin{abstract}
Because the web steel structure is introduced to our country for a short time, is still deficient in experimental research in China. Because the particularity and the structure of the system, there is no can be used to design the software of web steel structure design and the construction drawing, that influence the web steel structure application in china. The paper design and calculate the steel structure building using software SAP2000, and then using web steel structure drawing system design in this paper to connect with the SAP2000 model drawing file to construct drawing, the research results in this paper have some practical value for the web steel structure engineering design.
\end{abstract}

Keywords- Web-steel: AutoCAD secondary Development; Drawing system; Design

\section{INTRODUCTION}

Web steel structure system is a series of light steel keel structure construction technology. The system takes the coldformed thin-walled square steel tube through a connecting piece and a self-tapping screw column and floor truss beam as the main load-bearing frame, using skin connected to the monolithic column and square column by a self-tapping screw for retaining structure. The transfer mechanism is: the upright post and the upper and lower guide rail support skin bearing wall, vertical load is transferred to the wall studs through the floor truss beam, then to a foundation; horizontal load is transferred to the wall through the floor panels. Columns and skins covered on the upright posts together to resist horizontal load, which have a firm intensity, good shock resistance, high industrialization, short construction period, high recovery rate, heat and sound insulation effect is good, low cost advantages. In 2004, the structure system has been introduced into China from Canada, it have been very good application in recent years.

Because the web steel structure was introduced to China in a short time and the particularity and the structure of the system, less than in the experimental research in China, there is no available the construction drawing software for design of web steel structure. PKPM and other graphics software is better software, due to the inability to simulate web steel structure of important component of skin, so not suitable for web steel structure building design; simulation of SAP2000 finite element software can be more accurate web steel structure of all major components, can be used for the web steel structure building design, but this kind of software no mapping function. As such, this paper made the SAP2000 model file construction drawing web steel structure drawing system, so that it can use SAP2000 software for the web steel structure building design and calculation, draw the construction drawings of web steel structure drawing after the system is designed with the. The web steel structure mapping system is in practice, combining with the practical engineering needs to be developed, this system has been in trial. The research results in this paper have some practical value for the web steel structure engineering design.

\section{CALCULATION AND DESIGN OF WEB STEEL STRUCTURE}

Designers of web steel structures mainly include two parts: one is to design the structure of web steel structure building, two is the construction drawing. Among them, the first part using the general structural analysis and design of finite element software SAP2000 to complete, this chapter will introduce the very structure of steel structure design; the second part made by the web steel structure mapping system to complete, so steel structure drawing system of production and use method will be introduced in the fourth chapter. The design process: first the primary component size, location, and then using SAP2000 modeling calculation, calculation is completed for structural deformation, bearing capacity, whether meet the requirements specification and meet the construction drawing, if it is not meet the gravity component size, layout location, then it need re model and calculate, as shown in Figure 1.

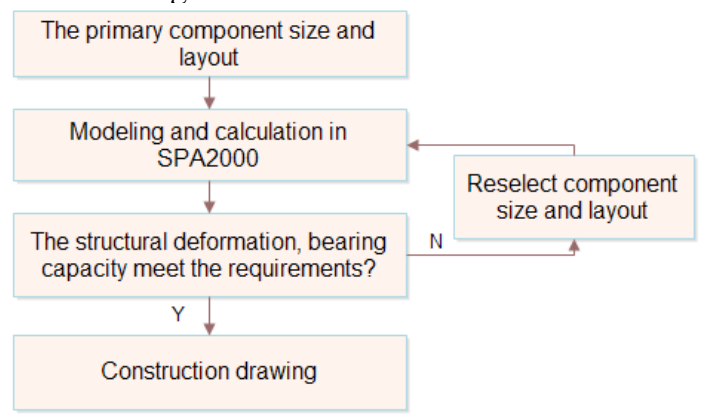

Fig.1 Structure design and flow chart of web steel structure buildings 


\section{A. Component specifications and recommended primary model in design}

So the main component of steel structure building includes skin, brace, cable-stayed steel, rail, truss beam, column (including square column and monolithic column). Skin can use gypsum board, bamboo mat plywood (bamboo) and oriented strand board (OSB board) three plates.

Skin thickness should generally not be less than $6 \mathrm{~mm}$, cable stayed steel section should not be less than $40 \mathrm{~mm} * 1.0$ $\mathrm{mm}$. C guide the thickness of desirable $1.0-1.5 \mathrm{~mm}$, the web width is $150 \mathrm{~mm}$ (non-load bearing walls) or $240 \mathrm{~mm}$ (bearing wall). Transverse bracing can use models $40 \mathrm{~mm} * 40 \mathrm{~mm} *$ $1.5 \mathrm{~m}$ thin-walled square steel tube.

Column center to center spacing is $200 \mathrm{~mm}$ and $110 \mathrm{~mm}$ two specifications, respectively used for load-bearing wall (wall thickness $240 \mathrm{~mm}$ ) and the non-load bearing wall (wall thickness $150 \mathrm{~mm}$ ) two kinds of wall. Column section size is generally fixed for $40 \mathrm{~mm} * 40 \mathrm{~mm}$ box, but can be used with wall thickness of $0.8-2.0 \mathrm{~mm}$, the $1.2 \mathrm{~mm}, 1.5 \mathrm{~mm}$ and $2.0 \mathrm{~mm}$. The column spacing is generally desirable $400 \mathrm{~mm}-600 \mathrm{~mm}$. Recommended web steel structure building design primary pipe wall thickness and the column spacing, see table 1 .

Table 1 Recommended wall thickness of primary pipe and column spacing

\begin{tabular}{c|c|c}
\hline All layer & $\begin{array}{c}\text { Tube wall } \\
\text { thickness }(\mathrm{mm})\end{array}$ & $\begin{array}{c}\text { The column } \\
\text { spacing }(\mathrm{mm})\end{array}$ \\
\hline 1.2 & 1.2 & 600 \\
\hline $3 、 4$ & 1.5 & 600 \\
\hline 5 & 1.5 & 500 \\
\hline 6 & 1.5 & 400 \\
\hline
\end{tabular}

Rectangular steel tube of beam section size upper chord truss are $40 \mathrm{~mm} * 40 \mathrm{~mm}, 40 \mathrm{~mm} * 60 \mathrm{~mm}, 40 \mathrm{~mm} * 80 \mathrm{~mm}$ three, rectangular steel pipe section size of bottom chord with $40 \mathrm{~mm} \times 40 \mathrm{~mm}, 40 \mathrm{~mm} \times 60 \mathrm{~mm}$ two, $40 \mathrm{mmx} 40 \mathrm{~mm}$, the size of web members $40 \mathrm{~mm} \times 60 \mathrm{~mm}, 40 \mathrm{~mm} \times 80 \mathrm{~mm}$ three. High of beam is generally $150 \mathrm{~mm}, 240 \mathrm{~mm}$ or $360 \mathrm{~mm}$, rectangular steel tube wall thickness is $0.8-2.0 \mathrm{~mm}$, the commonly used $1.5 \mathrm{~mm}$. Truss girder is generally arranged in columns (also can be arranged on the lintel), so the truss girder spacing is generally determined by the column spacing. Because the web steel truss beam top chord compression and lower chord tension rod is arranged, so the large section at the first reasonable. The doors and windows on the beam due to the larger force, generally uses the chord larger specification. Recommended primary models of truss girder in design is as in table 2.

Table 2 Recommended primary truss beam model and methods to improve the bearing capacity

\begin{tabular}{c|c|c|c|c}
\hline Truss girder & $\begin{array}{c}\text { Top chord } \\
(\mathrm{mm})\end{array}$ & $\begin{array}{c}\text { Bottom chord } \\
(\mathrm{mm})\end{array}$ & $\begin{array}{c}\text { Ventral rod } \\
(\mathrm{mm})\end{array}$ & $\begin{array}{c}\text { Method of increased } \\
\text { load capacity }\end{array}$ \\
\hline Lintel & $40 * 80 * 1.5$ & $40 * 60 * 1.5$ & $40 * 60 * 1.5$ & $\begin{array}{c}\text { Increasing the chord } \\
\text { thickness }\end{array}$ \\
\hline $\begin{array}{c}\text { Joist span less } \\
\text { than 3.6m }\end{array}$ & $40 * 40 * 1.5$ & $40 * 40 * 1.5$ & $40 * 40 * 1.5$ & $\begin{array}{c}\text { Increasing the chord } \\
\text { thickness }\end{array}$ \\
\hline $\begin{array}{c}\text { Joist span in } \\
3.6 \mathrm{~m}-4.5 \mathrm{~m}\end{array}$ & $40 * 60 * 1.5$ & $40 * 60 * 1.5$ & $40 * 60 * 1.5$ & $\begin{array}{c}\text { Increasing the top } \\
\text { chord or abdominal } \\
\text { rod wall thickness }\end{array}$ \\
\hline $\begin{array}{c}\text { Joist span } \\
\text { more than } \\
4.5 \mathrm{~m}\end{array}$ & $40 * 80 * 1.5$ & $40 * 60 * 1.5$ & $40 * 60 * 1.5$ & $\begin{array}{c}\text { Increased abdominal } \\
\text { rod wall thickness }\end{array}$ \\
\hline
\end{tabular}

\section{B. Material properties}

(1) The material properties of gypsum board. The gypsum board is a brittle material; the tensile strength is low, at the same time, gypsum board, longitudinal and transverse tensile strength of different, resulting in orthotropic properties of gypsum board material. Gypsum board has long used as building decoration materials, less research on the mechanical properties of the corresponding. Mechanical properties of gypsum board as shown in the reference [2]. Analysis of gypsum board material is assumed isotropic elastic material. According to the material properties of gypsum board considering isotropic material value can refer to table 3.

Table 3 Material properties of gypsum board according to the isotropic material

\begin{tabular}{c|c|c|c}
\hline $\begin{array}{c}\text { Modulus of elasticity } \\
\mathrm{N} / \mathrm{mm}^{2}\end{array}$ & $\begin{array}{c}\text { Poisson's } \\
\text { ratio }\end{array}$ & $\begin{array}{c}\text { Density } \\
\mathrm{kg} / \mathrm{m}^{3}\end{array}$ & $\begin{array}{c}\text { Severe } \\
\mathrm{kN} / \mathrm{m}^{3}\end{array}$ \\
\hline 641.7 & 0.23 & 1300 & 13 \\
\hline
\end{tabular}

(2) OSB plate material properties. Wood for anisotropic materials, when it's processing send into OSB plate, the original material properties have changed, which can be considered as an orthogonal anisotropic material. SAP2000 finite element analysis is OSB board for isotropic material, its material properties can refer to table 4 to select input.

Table 4 Material properties of OSB board according to the isotropic material

\begin{tabular}{c|c|c|c}
\hline $\begin{array}{c}\text { Modulus of elasticity } \\
\mathrm{N} / \mathrm{mm}^{2}\end{array}$ & $\begin{array}{c}\text { Poisson's } \\
\text { ratio }\end{array}$ & $\begin{array}{c}\text { Density } \\
\mathrm{kg} / \mathrm{m}^{3}\end{array}$ & $\begin{array}{c}\text { Severe } \\
\mathrm{kN} / \mathrm{m}^{3}\end{array}$ \\
\hline 1910 & 0.3 & 600 & 6 \\
\hline
\end{tabular}

(3) Bamboo material properties. The use of actual engineering in bamboo plywood is pressed out by bamboo plywood laminated bamboo products, bamboo fiber direction between layers are perpendicular to each other, in the whole stress, mechanical properties show close to orthogonal anisotropic material. Using the SAP2000 modeling analysis of bamboo plywood as isotropic material input, material properties can be selected according to table 5 .

Table 5 Material properties of Bamboo plywood according to the isotropic material

\begin{tabular}{c|c|c|c}
\hline $\begin{array}{c}\text { Modulus of elasticity } \\
\mathrm{N} / \mathrm{mm}^{2}\end{array}$ & $\begin{array}{c}\text { Poisson's } \\
\text { ratio }\end{array}$ & $\begin{array}{c}\text { Density } \\
\mathrm{kg} / \mathrm{m}^{3}\end{array}$ & $\begin{array}{c}\text { Severe } \\
\mathrm{kN} / \mathrm{m}^{3}\end{array}$ \\
\hline 6123 & 0.127 & 850 & 8.5 \\
\hline
\end{tabular}

(4) The material properties of steel members. Through the statistics and calculation can be obtained by the elastic modulus, yield strength and tensile strength. At the same time, the nominal length $\mathrm{L} 0$ can calculate the elongation of the material. So the steel structure material performance test result [3] is as shown in table 6. According to "load code for the design of building structures" (GB50009 - 2001) in Appendix A, steel severe uses $78.5 \mathrm{kN} / \mathrm{m} 3$. 
Table 6 the test results of material properties of steel

\begin{tabular}{c|c|c|c|c}
\hline Component & $\begin{array}{c}\text { Modulus of } \\
\text { elasticity N/mm }\end{array}$ & $\begin{array}{c}\text { Yield strength } \\
\mathrm{N} / \mathrm{mm}^{2}\end{array}$ & $\begin{array}{c}\text { Tensile strength } \\
\mathrm{N} / \mathrm{mm}^{2}\end{array}$ & $\begin{array}{c}\text { Tensile } \\
\text { rate }\end{array}$ \\
\hline $\begin{array}{c}\text { Square steel } \\
\text { tube }\end{array}$ & $2.02 * 10^{5}$ & 299.6 & 330.1 & $19 \%$ \\
\hline $\begin{array}{c}\text { Rectangular } \\
\text { steel tube }\end{array}$ & $2.42 * 10^{5}$ & 279.9 & 334.5 & $19 \%$ \\
\hline Connector & $2.45 * 10^{5}$ & 361.1 & 374.3 & $14 \%$ \\
\hline Steel strip & $1.75^{*} 10^{5}$ & 228.4 & 333.1 & $35 \%$ \\
\hline
\end{tabular}

C. Load value and combination.

It can refer to "Load code for the design of building structures".

(1) Constant load: The structure deadweight =the weight per unit volume of material*Component volume (1)

(2) Live loads.

1) Floor live load. The floor live load = floor live load value * floor area (2)

2) Roof live load. Roof live load $=$ roof live load value * roof area (3)

3) Snow load. Snow load standard roof horizontal projection on the surface of the value calculated:

$S_{K}=\mu_{\mathrm{r}} s_{0} \quad$ (4) .Wherein: $S_{K}$ : snow load standard value $K N / m^{2} ; \mu_{r}$ : distribution factor of snow; $s_{0}$ : snow pressure $K N / m^{2}$

(3) Wind load: $w_{k}=\beta_{z} \mu_{s} \mu_{z} w_{0}$

(5) .Wherein: $w_{k}$ :

Wind load standard value; $\beta_{z}$ : The wind vibration coefficient at height $Z ; \mu_{s}$ : Height variation factor of wind pressure; $w_{0}$ : Basic wind pressure

(4) Seismic load calculation with the bottom shear method

"Code for seismic design of buildings" (GB50011-2001) regulations, the height is not more than $40 \mathrm{~m}$, the shear deformation and the mass and stiffness along the height of structure with uniform distribution, and the structure is similar to the single particle system, simplify the calculation by the bottom shear method.

The structure of the total base shear can be calculated using the following equation: $F_{E K}=a_{1} G_{e q} \quad$ ( 5) . The equivalent seismic force $\mathrm{Fi}$ calculated in no $\mathrm{i}$ floor: $F_{i}=\frac{G_{i} H_{i}}{\sum_{j=1}^{n} G_{j} H_{j}} F_{E K}\left(1-\delta_{n}\right)$

Additional horizontal force in vertex: $\Delta F_{n}=\delta_{n} F_{E K}$

Wherein: ai- Seismic response coefficient with Ti, but cannot low $0.2 \alpha_{\max }$;

$T_{1}$ :Natural vibration period; $\delta_{n}$ :Additional seismic effect coefficient; $G_{e q}$ :The total gravity load; $G_{E}$ : Total gravity load of each layer; $G_{i} 、 G_{j}$ : Gravity load of NO. $i 、 j$ layer o; $H_{i} 、 \mathrm{H}_{j}$ : High of NO. $i, j$ layer.

(5) Load combinations. 1) for bearing capacity limit state, design of load effect combination value $S$ should be a combination of the following values that is most disadvantageous value to determined: combination is controlled by the variable load effect: $S=\gamma_{G} S_{G K}+\gamma_{Q 1} S_{Q 1 K}+\sum_{i=2}^{n} \gamma_{Q i} \psi_{c i} S_{Q i k}$

Controlled by the permanent load effect combination: $S=\gamma_{G} S_{G K}+\sum_{i=2}^{n} \gamma_{Q i} \psi_{c i} S_{Q i k}$

Wherein: $\gamma_{G}$ : The distribution coefficient of permanent loads; $\gamma_{Q i}$ : Partial coefficient of the No.i variable load; $S_{G K}$ : According to the permanent load standard value to calculated effect load GK; $S_{Q i k}$ : According to the variable load standard value to calculated effect load $Q i k ; \psi_{\text {ci }}$ : combination coefficient of variable load $Q \mathrm{i}$, Combined with steel structure roof live load, floor live load and snow load value coefficient is 0.7 , the value of wind load combination coefficient is 0.6 .

2) For normal use limit state standard portfolio, design value of load effect combination:

$$
S=S_{G K}+S_{Q \mathrm{ik}}+\sum_{\mathrm{i}=2}^{\mathrm{n}} \psi_{\mathrm{ci}} S_{Q \mathrm{ik}}
$$

(6) Bearing capacity calculation. Web steel rod is mainly affected by the axial force, bending moment and shear force is very small, the axial force component is calculated as follows:

1) The axial force component strength: $\sigma=\frac{N}{A_{0}} \leq f$ (10)

Wherein: $\sigma$ : direct stress; $N$ : axial tension, pressure; $A_{0}$ : The effective area component; $\mathrm{f}$ : The tensile strength of steel design value.

2) Axial compression member stability: $\frac{N}{\varphi A_{0}} \leq f$

Wherein: p: Stability coefficient of axial compression members.

\section{THE PROGRAM DESIGN AND IMPLEMENTATION}

When started drawing in system design, the system will pop-up dialog box, that is as shown in Figure 2, the title of the dialog box is "draw the plan," the painted floor in the SAPZ000 model floor bottom and top Z coordinates input request user in the edit box form, unit MRN, enter the digital, the default value difference is "0" and "3000". Name request user input to edit box on the form, the default value is 
"standard layer structure layout". Drawing in proportion to the edit box in the form of request user input, the default value is "50" said the plane drawing ratio is 1:50. Drawing format to radio button that lets users choose, can choose A0, A1, A2, A3 four kinds of drawings, the default selection A2 drawings.

The dialog box can be AutoLISP program and receive information:

(setq n 25 "to 50" bottom "0" top "3000"); to set the initial value

(setqname "layer structure layout map of standard")

(setq DCL (load_dialog "wbpmdcl.del")); load dialog file

(if (not (new_dialog "wbpmdcl" DCL (exit)))); start function wbpmdel, if failed, then exit procedures

(action_tile "Di" "(setqbottom\$value)"): edit box value

(action_tile," Ding", (setqtoP\$value) ")

(action_tile "name" "(setqname\$value)")

(action_tile "Bili" "(setqs\$value)")

(action_tile "A0" (setq N 0) ")

(action_tile "A1" (setq n 1) ")

(action_tile "A2" (setq N 2)")

Action_tile "A3" (setq n 3) ")

(setq oke (start_dialog)): startup dialog

(if (=oke 1) (progn; if the point OK button, then

(setq s (read s)); get the drawing ratio

(setq bottom (read bottom))

(setq top (read top))))

(unload_dialog DCL); unload dialog file

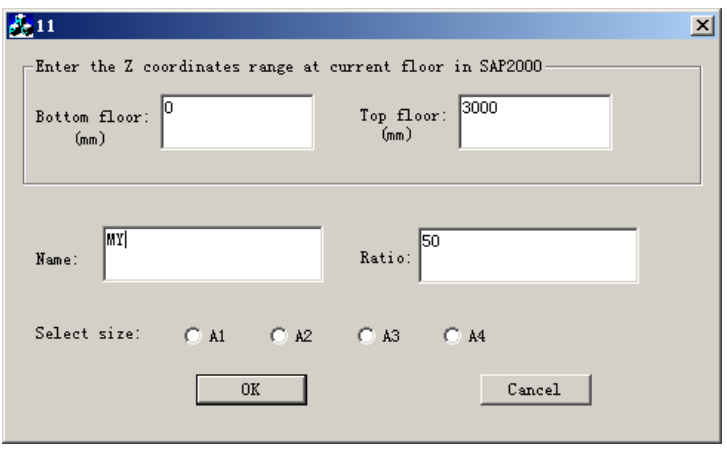

Fig.2 The plane design of dialogue

\section{CONCLUSIONS}

Through carries on secondary developments on AutoCAD, we set up a drawing system that can use to draw web-steel structure plan and $3 \mathrm{D}$ wall structure diagram of steel structure building that can be connected with the S02000 model file, the drawing system can complete web steel structure building construction drawing. The system has a certain practical value for the web steel structure engineering design.

\section{REFERENCE}

[1] Peng Junsheng, Luo Yongkun, Peng. Dynamics of structures, seismic calculation and application of SAP2000 [J]. Southwest Jiao Tong University press. 2007

[2] Zhao Jingliang. Two times the development technology of AutoCAD2OO4 and AutoLISP[J]. Tsinghua University press.2004

[3] Li Liping. Application of AutoLISP in the design of building structures [J]. The posts and Telecommunications Press.2003

[4] Jiang bin. Discussion on web steel green residential [J]. Engineering design.2006

[5] W.H.Thomas: Concentrated Load Capacity and Stiffness of Oriented Strand Board: Calculation Versus Test, Journal of Structural Engineering, vo1.128, No.ST7, July, 908-912,2002. 